\title{
Community-Centered, Internationalization at Home based Plan for the Global Student Citizenship
}

\author{
Helber Silva, Ph.D ${ }^{1}$, Marcelo Camilo, M.Sc ${ }^{1}$, and Keila Moreira, Ph.D. ${ }^{1}$ \\ ${ }^{1}$ Federal Institute of Education, Science and Technology (IFRN), Brazil \\ \{helber.silva,marcelo.camilo,keila.moreira\}@ifrn.edu.br
}

\begin{abstract}
Internationalization has brought benefits to educational institutions, such as international research and recognition of the international academic community, by favoring global student citizenship. However, reductions in government investment in student mobility and project funding limit initiatives, hampering the internationalization process and stimulating new forms to handle this issue. This work presents an inclusive, internationalization plan, called C2-IaH (Community-Centered Internationalization at Home), suitable for any professional education institution, whose actions are centered on the local community and based on Internationalization at Home approaches with lower financial investments. The C2-IaH presupposes integrating different teaching, research and extension actions, at multiple educational levels (vocational and higher education), with the participation of students (including foreigners) and traditional communities, to promote knowledge of additional languages and interculturality as engines of institutional internationalization. A local case study showed that actions linked to C2-IaH achieved effective results for the professional institution as a whole at a low level of investments.
\end{abstract}

Keywords-- Community-Centered Internationalization, Internationalization at Home, Internationalized Professional Education.

\section{INTRODUCTION}

When discussing the concept of internalization, it is necessary to be clear that there are several theoretical approaches and initiatives, the majority focused on higher education, mainly linked to postgraduate studies [1-5]. This observation makes the challenge of internationalizing an educational institution as a whole even more challenging, especially considering Brazil's Basic Education and its historical limitations

For Knight [6], internationalization, from a national, sectoral and institutional perspective, is defined as the process in which an international, intercultural or global dimension is integrated into the purposes, functions and offers of postsecondary education. Within this conceptualization one can understand that internationalization would achieve integration processes in several actions that go beyond academic mobility, collaborative research, curricular aspects for courses and programs of disciplines focused on internationalization and, within our scope, not only post-secondary education, but anticipating this process by making it more effective to achieve.

The Federal Network of Technological Education Institutions in Brazil has the enormous potential of internationalization. On the one hand, this is due to their perspective of professional education in multiple levels of education (vocational, undergraduate, masters and doctorate). On the other hand, the Federal Network currently covers more than 640 campuses installed in more than 560 municipalities in all Brazilian states. Due to its capillarity, it is a widely spread professional educational network with quality that has been socially referenced throughout the more than 100 years of existence. In addition, the Federal Network develops professional activities covering fundamental principles in teaching, scientific research and extension.

However, the recent policy of the Federal Government of Brazil has been austerity, reducing investments in the institutions of the Federal Network, of which the Federal Institute of Education, Science and Technology of Rio Grande do Norte - IFRN (locus of the study in this work) forms part. As a result, opportunities for student mobility, for example, become increasingly limited or even non-existent. It is therefore necessary to identify and apply alternative ways of promoting internationalization.

Based on all these concepts, benefits and challenges related to the internationalization of educational institutions, the main problem addressed in this work is to determine how to strengthen the internationalization of the IFRN to a low level of investment. The focus is on encouraging teachers and students to develop concrete actions of teaching, research and extension based on Internationalization at Home (IaH) [7], including at the same time the diversity inherent in the people of the communities nearby the IFRN campuses. Thus, the investigations seek to offer answers to the following research questions: (i) is it feasible to integrate multiple educational levels into an action based on $\mathrm{IaH}$ ? and (ii) what are the possible educational gains in integrating students and the external community (i.e., non-IFRN students) into IFRN internationalization?

Given the problem to be solved and from the research questions raised, this paper presents the contributions described below:

- description of an internationalization plan, called C2$\mathrm{IaH}$ (Community-Centered Internationalization at Home), inclusive, centered on the local community and based on $\mathrm{IaH}$ for "internationalized" teaching, research and extension of any professional education institution; and

- analysis of a local case study including teaching, research and extension actions based on the $\mathrm{C} 2-\mathrm{IaH}$ plan, in the context of an IFRN campus. 
The remainder of the paper is organized as follows. Section II presents the C2-IaH internationalization plan proposed in this paper. Section III details a case study of the $\mathrm{C} 2$-IaH plan with teaching, research and extension actions carried out at the Canguaretama Campus at IFRN. Finally, Section IV presents the conclusions and future work.

\section{THE C2-IAH INTERNATIONALIZATION PLAN}

This section presents the internationalization plan, called Community-Centered Internationalization at Home (C2-IaH), proposed in this paper, that aims at strengthening the internationalization of any professional education institution to a low investment, in light of the research questions raised in Section I of this work. To this end, C2-IaH is based on processes that aim to broaden the scope of inclusive and community-centered actions in which the institution is installed. The $\mathrm{C} 2-\mathrm{IaH}$ plan should encompass different actions (which we called C2-IaH actions) that involve the fundamental principles of teaching, research and extension, in isolation or concomitantly (i.e, encompassing more than one principle in the same action), using strategies of $\mathrm{IaH}$.

Fig. 1 presents the $\mathrm{C} 2-\mathrm{IaH}$ internationalization model, which represents the main contribution of this work. The figure also illustrates a case study of the application of $\mathrm{C} 2$-IaH in one of the IFRN campuses, specifically the Canguaretama Campus. The C2-IaH actions effectively performed in the case study are fully described in Section III of this paper.

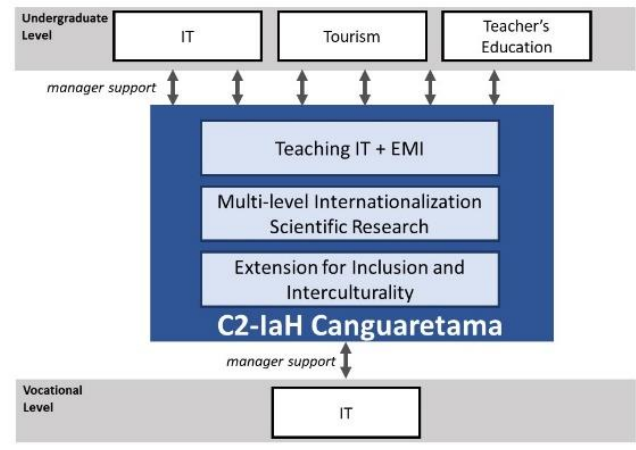

Fig. 1. The proposed C2-IaH internationalization plan.

It can be observed in Fig. 1 that the educational levels (in the case study, technological graduation and vocationals) involved in the $\mathrm{C} 2-\mathrm{IaH}$ actions are shown at the top and bottom of the figure, respectively. These levels cover the teams formed by teachers and students who effectively develop C2-IaH actions, with the institutional support of management (e.g, direction and pedagogical coordination) in the financing and/or monitoring of teams. At the center of Fig. 1 is shown the $\mathrm{C} 2-\mathrm{IaH}$ plan, which should be implemented in the form of effective actions in the institution.

The participation of the external community (i.e., nonstudents in the institution) is a fundamental requirement in the design of C2-IaH. This requirement stems from the conception of the internationalization plan, which is centered on the (external) community. The idea behind this fundamental requirement is to promote internationalization taking into account the diversity (ethnic, cultural, economic and etc.) nearby the institution, which tends to increase the interculturality of individuals, thus favoring the global citizenship of these people. Global citizenship is achieved when the individual understands the globalized world, uses self-criticism, reflects and performs actions to solve local and global problems [8].

From the conceptual point of view, the C2-IaH represents an internationalization plan guided by different processes, from favoring the understanding of its importance (by the internal and external communities) to analyzing the results of $\mathrm{C} 2$-IaH actions. The optimal case is one where the processes direct the totality of teachers and students, of all levels, in different actions C2-IaH. Such actions have to involve both the internal community and the outside community. In this work, the internal community includes teachers, servants (e.g., pedagogues, managers and etc.) and students regularly enrolled in the IFRN. The external community, on the other hand, includes individuals or associations (e.g, landless, indigenous, quilombolas, etc.) who may relate to a $\mathrm{C} 2-\mathrm{IaH}$ action on each campus, even if they do not participate in the internal community of the IFRN.

Given these characteristics inherent to $\mathrm{C} 2-\mathrm{IaH}$, the first process to be considered should be to make it understandable (i.e., convincing about its relevance) to the internal and external communities of an IFRN campus. This process, that we name Comprehensive C2-IaH process, has as main objective to stimulate the participation of teachers, students and external community in the participation of C2-IaH actions. This is required since the internationalization is not a widely understood concept and a number of people do not know the benefits it can bring for themselves. To this end, actions need to address key requirements, including:

- internationalization (especially through $\mathrm{IaH}$ ) should be understood as a concrete possibility for anyone, regardless of age, race, religion or socio-economic situation; and

- global citizenship can be achieved by internationalizing individuals at low investment.

Fig. 2 shows the sequence diagram of the Comprehensive $\mathrm{C} 2-\mathrm{IaH}$, identifying the actors and sequenced activities. In this process, the actors are as follows: (i) Internal and External Communities, (ii) Responsible Team, and (iii) Campus Management. The External Community in this process should be as comprehensive as possible, since the main purpose is to convince people of the relevance (to them) of the internationalization offered, through a $\mathrm{C} 2-\mathrm{IaH}$ action. The Responsible Team includes teacher, students, servants and etc. that design, execute and evaluate the results of an C2-IaH action. The Responsible Team is a subset of the Internal Community in the institution. The Campus Management can cover administrative sectors with access to financial resources (e.g, for material purchases, contracting of consultants, etc.)

$1^{\text {th }}$ LACCEI International Multi-Conference for Engineering, Education, and Technology: "Innovation in Education and Inclusion", 19-21 July 2018, Lima, Peru. 
and/or support teams (e.g, for logistics, accreditation, etc.) for the Responsible Team.

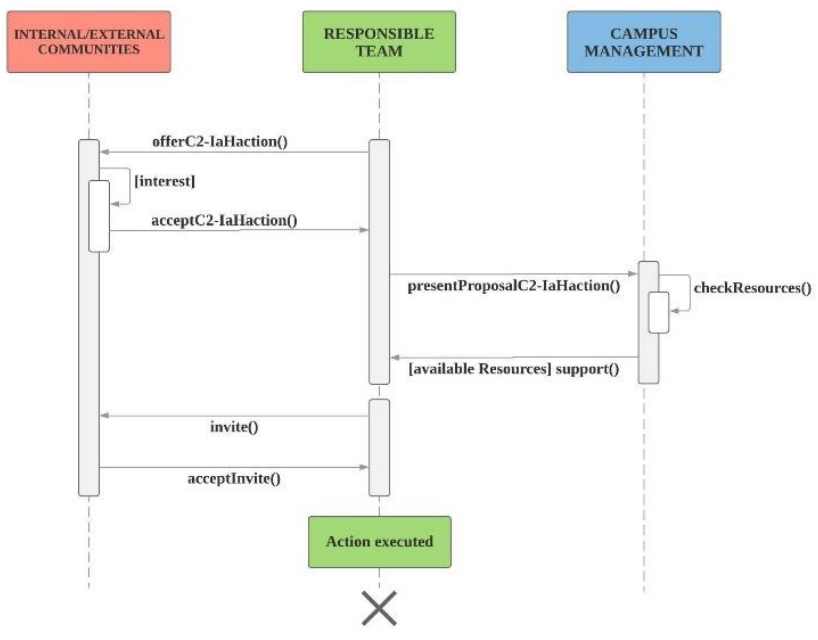

Fig.2. Sequence diagram - Comprehensive C2-IaH process.

The first activity of the Comprehensive C2-IaH process is to present and offer an $\mathrm{C} 2-\mathrm{IaH}$ action, previously planned by the Responsible Team, to the Internal/External Communities. This activity may include the dissemination of the $\mathrm{C} 2-\mathrm{IaH}$ action through traditional mass media (e.g, radio and television) in the campus neighborhood, institutional virtual social networks (e.g, Facebook, Instagram, WhatsApp, etc.), specific sites in the Internet or in the institutional web portal, among others. The expected result is the acceptance of the Internal/External Communities in participating in the planned C2-IaH action.

With the confirmation of the Internal/External Communities, the Responsible Team should be able to identify the characteristics (e.g, socioeconomic status, educational profile, age, stakeholder, etc.) of the target audience. The Responsible Team then submits to the Campus Management the $\mathrm{C} 2$-IaH action proposal, together with the specifications of the resources required for execution. Such specifications should be provisioned according to the characteristics of the target audience.

The C2-IaH action proposal should be composed of fundamental elements, such as justification, objectives, expected results, activities and goals, execution schedule and necessary resources, so that the Campus Management is able to evaluate the availability (total or partial) of resources. The expected result is the identification of the resources actually available to support the proposed action.

Knowing the target audience and the available resources, the Responsible Team invites the Internal/External Communities (through traditional, online communication and etc.) to participate in the planned action. This invitation must include all the necessary information (date, time, place, clothing, among others specific to the action). The expected result is the adhesion to the $\mathrm{C} 2-\mathrm{IaH}$ action, which will then be executed and will have its results evaluated by the Responsible Team for future actions.

The next section describes a set of $\mathrm{C} 2$-IaH-based actions, which may be considered effective examples, carried out based on the $\mathrm{C} 2-\mathrm{IaH}$ internationalization plan, as a case study at one of the IFRN campuses (particularly the Canguaretama Campus).

\section{CASE StUdy - THE CANGUARETAMA CAMPUS AT IFRN}

This section describes a set of three C2-IaH actions that were planned and effectively carried out, considering the IFRN as a case study. Specifically, the C2-IaH actions were carried out at the Canguaretama Campus. The following subsections describe the IFRN and the Canguaretama Campus, further detailing one different $\mathrm{C} 2-\mathrm{IaH}$ action for each of the three fundamental IFRN principles: teaching, research and extension.

\section{A. Institution Characterization}

The IFRN is a node of the Federal Network that covers, until the beginning of 2018, a total of 21 campuses (including the Rectory). These campuses are installed in all regions of the State of Rio Grande do Norte (Northeast Brazil), totaling around 2,000 teachers, 1,800 technicians and benefiting more than 40,000 students. In addition, the IFRN is a teaching institution classified as public, where in Brazil there are no monthly fees to be paid by students. Other characteristics of the internationalization were considered to conduct this work in the IFRN, including:

- Internationalization is present in the IFRN guidelines. This means that internationalization is one of IFRN's institutional policies. The main objective of this policy is to favor the development of local actions (i.e., considering the participation of students in the community where they reside) focusing on solving global problems, thus preparing them for global citizenship. For the better management of internationalization policies, an International Relations Department, linked to the IFRN Rectory, organizes, stimulates, systematizes, analyzes and evaluates the results of internationalization actions carried out by all the campuses. These actions can be based on internationalization at home, interchange, interinstitutional research and innovation projects with partners abroad, language-based teaching, intercultural events, among many others;

- The IFRN allows the student to verticalize their academic training. At the end of professional technical courses (typically vocationals lasting 4 years), students can continue their training by joining courses in their undergraduate level (between 3 and 4 years), masters (2 years) and $\mathrm{PhD}$ (5 years). This allows a young 14-year-old student to study for about 14 or 15 years at the IFRN. In the context of internationalization, therefore, developing actions

16 $^{\text {th }}$ LACCEI International Multi-Conference for Engineering, Education, and Technology: "Innovation in Education and Inclusion", 19-21 July 2018, Lima, Peru. 
since vocationals has the potential to greatly increase the international level of young students, especially in technical areas;

- The Political-Pedagogical Project (main guideline of the institution) assumes the integration, in a same course, of the human formation with the professional formation. With this, teaching can take advantage of techniques, such as CLIL, to favor the delivery of content through an additional language.

The following subsections detail the C2-IaH actions developed at the Canguaretama Campus.

\section{B. Teaching C2-IaH based on additional language}

One of the main work fronts for internationalization of the IFRN is to develop effective actions within the teachinglearning process. In this context and based on the model of the C2-IaH internationalization plan shown previously in Fig. 1, we developed a C2-IaH action based on CLIL (Content and Language Integrated Learning) in the Canguaretama Campus, where vocational students in Information Technology (IT) received technical content using an additional language (in the case, English).

The main objective of this C2-IaH action was to offer to the students of the professional course the content of the discipline of Computer Networks, during the period of 1 year, stimulating the conversation, reading and writing concepts using English. Such discipline was selected because it is strongly associated with terminologies and concepts defined in the English language. Specifically, this C2-IaH action in teaching was conceived based on the strategies defined within the scope of the EMI (English as a Medium of Instruction) pedagogical framework [9].

The main objective of EMI framework, which is considered a type of CLIL, is to encourage students to develop conversation, writing and reading in English as an additional (i.e., non-native) language, while maintaining a focus on the content delivery by the teacher. In the context of this specific C2-IaH action, the teacher used slides written in the English language, seminars where students were encouraged to discuss technical concepts in English, theoretical exercises whose statements and answers needed to be written in English, analysis of spoken technical videos in English and hosted on YouTube, tests using games (e.g, Kahoot), among other EMIbased strategies.

To make this action possible and feasible, it was necessary to carry out the C2-IaH Comprehensible process with students and Campus Management. The result of this process was that the students not only felt challenged, but also agreed to participate in the C2-IaH action. Specifically, the process was performed in the following steps:

1. The teacher verified, together with the Campus Management, if the application of the EMI approach in vocational courses would be allowed within the institutional guidelines, then receiving positive confirmation;

2. On the first day of the course, the teacher showed the students practical examples that the content of the discipline was associated with numerous terminologies and concepts in English, highlighting the importance of the language in the context of the discipline and for their educational formation;

3. On the second day of the course, students were offered scholarship opportunities in overseas programs (e.g, Young Ambassadors, Young Yale Global Scholars, among others), which require familiarity with the English language;

4. At the third meeting, the teacher proposed to students the work using the EMI approach during the remainder of the course, making it clear that benchmarking of student performance would not take into account the English language, since the course at IFRN is based in the native language (Portuguese).

It is important to emphasize that the teacher of the discipline based on the EMI has training in the area of Computer Science. Also because of this, it does not have the highest level of proficiency in the English language. However, by having a level considered intermediate in the language, he was able to develop the discipline within the purposes of EMI. This means that this approach can be applied in any discipline, by any teacher, as long as the English language is relevant in its concepts and is useful to students.

\section{Multi-level, intercampuses C2-IaH scientific research}

A scientific research based on $\mathrm{C} 2-\mathrm{IaH}$ was conducted using the teaching experience described in the previous section. The objective of the research was to verify the students' understanding of the advantages of internationalization at home, from a C2-IaH action in education. This survey was conducted with vocational students (who had discipline with EMI) and other undergraduate IT students (who had no prior EMI discipline experience). This scientific research involved three different IFRN campuses. The Canguaretama Campus was the locus of the course based on EMI. On the other hand, the Natal-Central and Natal-Zona Norte campuses (both located in the state capital, in the city of Natal) included students from undergraduate courses that participated in the research.

The main findings in the research can be summarized in the main points: (i) vocational students realized the importance of EMI in their training; and (ii) undergraduate students believe that an EMI-based course can expand their opportunities, including international ones, if there is such an offer at the IFRN. All the details of the research and the results can be analyzed in our previous work in [10]. 


\section{A C2-IaH Extension for inclusion and interculturality}

Another C2-IaH action, though of an extensionist nature (i.e., strongly encompassing the External Community), was carried out at the Canguaretama Campus. This action had the main objective of promoting interculturality among individuals of different nationalities and ethnicities, in the perspective of the exchange of knowledge between people for the social and educational development of peoples. Specifically, action C2-IaH included the execution of an event that brought together the following people:

- a group of (foreign) exchange students in the IFRN, that came from different countries (External Community);

- traditional communities in the region, specifically quilombolas and indigenous (External Community); and

- students of the professional and higher education of the Canguaretama Campus (Internal Community).

As an initial and necessary part of the planning of this $\mathrm{C} 2$ $\mathrm{IaH}$ action, the $\mathrm{C} 2-\mathrm{IaH}$ Comprehensive process was developed as follows:

1. The teacher interested in promoting the event invited a group of teachers from the Natal-Central campuses (responsible for exchange students at the IFRN) and also students from the Canguaretama Campus (who work in the field of Tourism and Events), identifying the objectives and the expected results from the event;

2. After confirmation of interest of such groups, the Campus Management (at Canguaretama Campus) was consulted to enable physical spaces and servers in support of the activities of the event.

The result of this process was the planned event and with institutional support ensured. Fig. 3 shows the event's flyer for the internal and external communities.

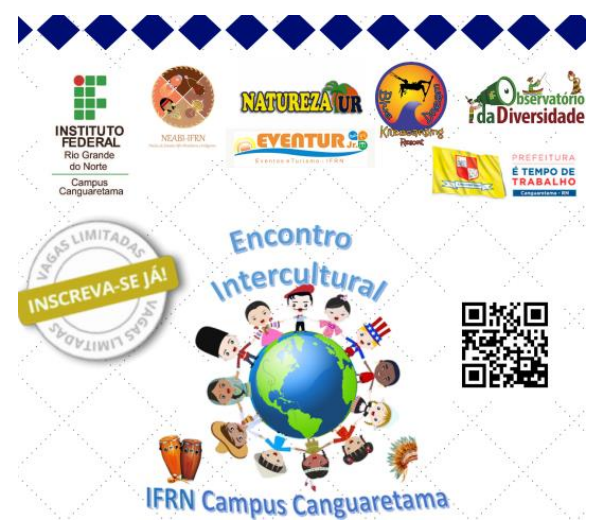

Fig.3. Event advertising flyer based on C2-IaH.
The event brought together a total of 19 exchange students from 14 different countries, all aged between 14 and 18 years. The first part of the event was to conduct an ecological trail in the Catu dos Eleotéreos indigenous community, where the foreign students and descendants of indigenous people interacted together in the exchange of knowledge among them, also visited an indigenous school and held a painting workshop. The foreign students then visited the Canguaretama Campus, where they participated in a conference on traditional communities and were also able to express their observations on the differences between cultures. After that, all the participants were able to participate in an activity of Coco de Zambê and capoeira (two traditional dances of the quilombola community of the region), as shown in the picture of the Fig. 4 below.

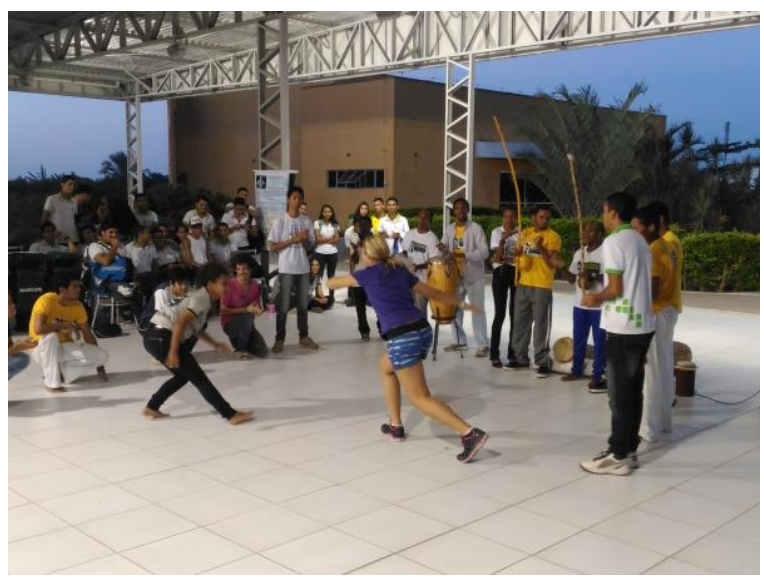

Fig. 4. Foreign student dancing Capoeira with students and quilombolas in the Canguaretama Campus in a C2-IaH extension action.

\section{CONCLUSION}

The internationalization of educational institutions can bring numerous benefits, not only to students and teachers but also to the external community that is not directly enrolled in any institutional education program. Even in the face of reduced investment, it is necessary to identify other ways of encouraging the internationalization of institutions. This paper presented a Community-Centered Internationalization at Home internationalization plan (the $\mathrm{C} 2-\mathrm{IaH}$ ) that seeks to reach students of multiple educational levels and community individuals residing in the vicinity of a professional education institution, expanding opportunities to internationalize these individuals in the context of global citizenship.

A case study of the C2-IaH internationalization plan has shown to be feasible to develop effective actions in teaching, research and extension, involving vocationals and undergraduate students, teachers, school management and traditional communities. Future work includes investigating processes of engagement of other teachers and managers from other educational institutions, even outside Brazil, in designing and executing actions based on the C2-IaH plan.

$1^{\text {th }}$ LACCEI International Multi-Conference for Engineering, Education, and Technology: "Innovation in Education and Inclusion", 19-21 July 2018, Lima, Peru. 


\section{REFERENCES}

[1] S. Khoo, L. Taylor, V. Andreotti, "Ethical Internationalization, Neoliberal Restructuring and "Beating the Bounds" of Higher Education", Assembling and Governing the Higher Education Institution, Palgrave Macmillan UK, p. 85-110, 2016.

[2] S. Mertkan, I. Gilanlioglu, S. McGrath, S. McGrath, "Internationalizing higher education: from grand plans to evolving responses", Journal of Organizational Change Management, vol. 29, n. 6, p. 889-902, 2016.

[3] J. Knight, "Internationalization: A decade of changes and challenges," International Higher Education, vol. 50, 2015.

[4] K. Soria, T. Jordan, "Internationalization at home alternatives to study abroad: Implications for students' development of global, international, and intercultural competencies." Journal of Studies in International Education, vol. 18, n. 3, pp 261-280, 2014.

[5] N. Armstrong, L. Napaporn, "Internationalization of Higher Education: Case Studies of Thailand and Malaysia", Scholar, vol. 8, n. 1, p. 102, 2016.

[6] J. Knight, "Internationalization remodeled: definition, approaches, and rationales", Journal of Studies in International Education, v. 8, n. 1, 2004.

[7] K. Soria, J. Troisi, "Internationalization at home alternatives to study abroad: Implications for students' development of global, international, and intercultural competencies", Journal of Studies in International Education, v. 18, n. 3, p. 261-280, 2014.

[8] V. Andreotti, "Soft versus critical global citizenship education", Development education in policy and practice, p. 21-31, 2016 .

[9] J. Dearden, "English as a medium of instruction-a growing global phenomenon", British Council. Online: https://www.britishcouncil.org/sites/default/files/e484_emi__cover_option_3_final_web.pdf (accessed 2/23/2018) (2015).

[10] H. Silva, M. Camilo, K. Moreira. "Improving Higher Education Internationalization through CLIL at the Secondary Level", Proceedings of the 15th LACCEI International Multi-Conference for Engineering, Education and Technology (LACCEI), 2017.

16 $^{\text {th }}$ LACCEI International Multi-Conference for Engineering, Education, and Technology: "Innovation in Education and Inclusion", 19-21 July 2018, Lima, Peru. 